\title{
TECNOLOGÍA DE LA INFORMACIÓN
}

\author{
Hugo Alberto Figueroa Alcántaral \\ César Augusto Ramírez Velázquez (Coordinadores) \\ Ed. Facultad de Filosofía y Letras., \\ UNAM., México., 2007., 163 p.
}

\section{DATOS DE LOS COORDINADORES DE LA OBRA}

Hugo Alberto Figueroa Alcántara es profesor de la Facultad de Filosofía y Letras de la Universidad Nacional Autónoma de México (UNAM) e imparte cursos en el Colegio de Bibliotecología.

César Augusto Ramírez Velázquez es investigador de carrera del Centro Universitario de Investigaciones Bibliotecológicas (UNAM). Actualmente es coordinador del Colegio de Bibliotecología.

\section{CONTENIDO}

La elección de esta obra, Tecnología de la información, responde al interés por mostrar cuáles son las posibilidades de las bibliotecas en donde se ha optado por la automatización de sus procesos a través de la tecnología de la información, y cómo este saber resulta fundamental para lo interesados en la educación y la investigación, pues son estos espacios los que albergan parte del conocimiento.

El texto presenta varios artículos. El primero se titula «Automatización de bibliotecas», escrito por Marcos René Álvarez Moreno, profesor del Colegio de Bibliotecología de la Facultad de 
Filosofía y Letras (UNAM). Aquí se explican brevemente las características de los sistemas comerciales para la gestión de bibliotecas como: Aleph, Altair, Biblio30000, Logicat, Micro CDS/ISIS, Sabini, Siabuc, Sistema Horizonte y Unicorn. Además, se exponen los elementos a considerar en un sistema de gestión de bibliotecas. Finalmente se explican los requerimientos de cómputo para dicho sistema.

El segundo apartado se titula «Seguridad en informática», escrito por Gonzalo Reséndiz Cansino, subdirector de Informática de la Dirección General de Bibliotecas (UNAM). Aquí se hace un recorrido histórico sobre la evolución de las computadoras y de Internet. El autor muestra la importancia de la seguridad en las redes computacionales, para dar paso a los conceptos de seguridad informática. La parte final presenta un plan de contingencias.

El tercer escrito se titula «Recursos digitales y multimedia» y lo escriben Verónica Méndez Ortiz, Lizet Anayivi Ruiz Hernández y Hugo Alberto Figueroa Alcántara, todos adscritos al Colegio de Bibliotecología de la Facultad de Filosofía y Letras (UNAM). Los autores definen conceptos sobre multimedia, hipertexto, hipermedia y recursos digitales. Es un apartado con información básica para personas que no han tenido contacto con estos conceptos.

El siguiente artículo, «Las bibliotecas y el bibliotecario profesional en la era digital», lo escribe Juan Voutssás Márquez, doctor en Bibliotecología y Estudios de la Información por la Facultad de Filosofía y Letras (UNAM). La reflexión de este apartado gira en torno a Internet y las bibliotecas digitales. El autor captura la atención a través de narrar una historia sobre dos estudiantes que conversan acerca de cómo realizar un trabajo escolar. Así, Juan Voutssás Márquez muestra la preocupación por la repetición de patrones de algunos alumnos que sólo se dedican a copiar información: antes lo hacían con recursos analógicos, ahora, con recursos digitales.

La intención es analizar el fenómeno de la globalización y su impacto en la conformación de la biblioteca digital. «[...] entre los fenómenos más significativos derivados de la globalización se encuentra la globalización 
de la información; es decir, el hecho de que podemos acceder instantáneamente, desde nuestra casa o trabajo, a información generada en múltiples lugares del mundo» (p. 76).

El camino para reflexionar sobre el concepto de biblioteca digital es: primero definir qué es una biblioteca automatizada; en segundo lugar, presenta el concepto de biblioteca electrónica, y finalmente, analiza el concepto de biblioteca virtual.

Así, el artículo de Voutssás es una respuesta a quienes conciben a Internet como una biblioteca digital. El autor enfatiza que no todo lo que está en la web es información académica o científica, ya que el buscar información seria de manera tan abierta, dificulta su registro: es imposible un control de calidad sobre todo lo que se sube a la Red, además de que no todas las publicaciones impresas se encuentran en versión digital.

En este mismo apartado se rescatan los elementos primordiales que conforman una biblioteca digital: una colección de objetos de información, una colección de servicios, unos usuarios, la organización, la presentación de los objetos, y un sistema para ordenar y presentar dichos objetos.

También presenta una serie de cuestionamientos que permiten evaluar sitios web ?los cuales muchas veces se hacen llamar «bibliotecas digitales»? a través de preguntas como: ¿Qué nos dice el URL o dirección web? ¿Quiénes patrocinan esa página? ¿Está señalado quién escribió la página? ¿Cuál es su alcance? ¿Cuenta con un cuerpo editorial? ¿El sitio es recomendado? ¿Cuál es la intención del sitio?, entre muchas otras.

El siguiente trabajo lo escriben Brenda Cabral Vargas, Reyna Ramírez Medina y Hugo Alberto Figueroa Alcántara y se titula «La biblioteca digital». Brenda Cabral es investigadora del Centro Universitario de Instigaciones Bibliotecológicas de la UNAM. Reyna Ramírez colabora en el Colegio de Bibliotecología de la FFyL (UNAM) y Hugo Figueroa es profesor de tiempo completo del Colegio de Bibliotecología de la fiel (UNAM). 
Estos autores presentan, desde una perspectiva bibliotecológicasocial, como ellos lo mencionan, un panorama sobre las bibliotecas digitales: sus características, los elementos involucrados en su creación y desarrollo, las ventajas que poseen y sus tendencias.

Finalmente, el último apartado, a cargo de Miguel Ángel Amaya Ramírez, «La web invisible: búsqueda y recuperación de información oculta por medio de los buscadores convencionales», tiene como objetivo mostrar métodos, técnicas y herramientas de recuperación de información de calidad.

A manera de cierre señalaremos que este libro puede recomendarse a todo aquel que se dedica a la investigación, principalmente documental.

Claudia F. Ortega B. 